\title{
Biological Impact of Unilateral Oophorectomy: Does the Number of Ovaries Really Matter?
}

\section{Biologische Auswirkungen der einseitigen Ovarektomie: Kommt es wirklich auf die Anzahl der Eierstöcke an?}

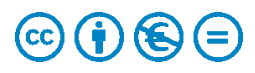

Authors

Maria Luisa Gasparri ${ }^{1 *}$, Ilary Ruscito ${ }^{2,3 *}$, Elena Ioana Braicu ${ }^{3}$, Jalid Sehouli ${ }^{3}$, Luca Tramontano ${ }^{1}$, Flavia Costanzi ${ }^{2}$, Maria Paola De Marco ${ }^{2}$, Michael D. Mueller ${ }^{4}$, Andrea Papadia ${ }^{1}$, Donatella Caserta $^{2 *}$, Filippo Bellati $^{2 * *}$

Affiliations

1 Department of Obstetrics and Gynecology, Ente Ospedaliero Cantonale (EOC), Università Svizzera Italiana, Lugano, Switzerland

2 Gynecologic Division, Department of Medical and Surgical Sciences and Translational Medicine, Sant'Andrea University Hospital, Sapienza University of Rome, Rome, Italy

3 Department of Gynaecology, European Competence Center for Ovarian Cancer, Campus Virchow Clinic, Charité - Universitätsmedizin Berlin, Berlin, Germany

4 Department of Obstetrics and Gynaecology, University Hospital of Berne and University of Berne, Berne, Switzerland

\section{Key words}

unilateral oophorectomy, fertility, IVF, pregnancy rate, conservative surgery, ovarian cystectomy

\section{Schlüsselwörter}

einseitige Ovarektomie, Fertilität, IVF, Schwangerschaftsrate, konservative Chirurge, ovarielle Zystektomie

$\begin{array}{ll}\text { received } & 13.5 .2020 \\ \text { accepted after revision } & 11.8 .2020 \\ \text { published online } & 1.10 .2020\end{array}$

Bibliography

Geburtsh Frauenheilk 2021; 81: 331-338

DOI 10.1055/a-1239-3958

ISSN 0016-5751

(C) 2020. The Author(s).

This is an open access article published by Thieme under the terms of the Creative Commons Attribution-NonDerivative-NonCommercial-License, permitting copying and reproduction so long as the original work is given appropriate credit. Contents may not be used for commercial purposes, or adapted, remixed, transformed or built upon. (https://creativecommons.org/licenses/by-nc-nd/4.0/)

Georg Thieme Verlag KG, Rüdigerstraße 14,

70469 Stuttgart, Germany

\footnotetext{
* These two authors contributed equally to this work.
}

** These two authors contributed equally to this work.
Correspondence

Dr. Ilary Ruscito

Gynecologic Division, Department of Medical and Surgical

Sciences and Translational Medicine, Sant'Andrea University

Hospital, Sapienza University of Rome

Via di Grottarossa 1035, 00189, Rome, Italy

ilary.ruscito@uniroma1.it

\section{ABSTRACT}

Although unilateral oophorectomies are performed more often than bilateral ones in women of reproductive age, their clinical consequences have been less intensively investigated. Experimental models in animals have shown that compensatory mechanisms occur after a unilateral oophorectomy (UO). This review aims to summarize the available evidence on the biological effects of unilateral oophorectomy on women. Evaluated outcomes include age at onset of menopause, risk of cardiovascular and neurological disease, risk of mortality and fertility outcome after spontaneous conception or in vitro fertilization (IVF). Results were compared with findings reported after bilateral oophorectomy and/or ovarian excision and/or women with intact ovaries. An electronic database search was performed using PubMed and Scopus, followed by a manual search to identify controlled studies that compared women after UO with women with two intact ovaries. In particular, a systematic review of fertility outcomes after IVF was performed, and the data were summarized in a table. Women who underwent UO had a similar age at menopause and similar clinical pregnancy rate compared to women with two ovaries. However, decreased ovarian reserve affecting the quantity but not the quality of the ovarian pool after IVF was observed in the UO group. Furthermore, an increased risk of neurological disease and even an increased risk of mortality was observed in women with single ovary. These data need to be confirmed by further studies, and a plausible mechanism of action must be identified. At present, patients who undergo UO can be reassured with regard to their reproductive potential and their age at onset of menopause. 


\section{ZUSAMMENFASSUNG}

Obwohl einseitige Ovarektomien häufiger als bilaterale Eierstockentfernungen bei Frauen im reproduktionsfähigen Alter durchgeführt werden, hat man den klinischen Folgen von einseitigen Ovarektomien weniger Aufmerksamkeit gewidmet. Experimentelle Tiermodelle zeigen, dass Kompensationsmechanismen nach einseitigen Ovarektomien stattfinden. Ziel dieser Übersichtsarbeit war es, die existierenden Forschungsergebnisse zu den biologischen Auswirkungen von einseitigen Ovarektomien zusammenzufassen. Zu den untersuchten Aspekten zählten Alter bei Eintritt der Wechseljahre, Risiko für Herz-Kreislauf-Erkrankungen und neurologische Erkrankungen, Mortalitätsrisiko und Fertilitätsergebnis nach spontaner Empfängnis oder In-vitro-Fertilisation (IVF). Diese Ergebnisse wurden mit den Ergebnissen nach bilateraler Ovarektomie und/oder ovarieller Exzision bzw. von Frauen mit intakten Eierstöcken verglichen. Es wurde zunächst eine elektronische Datenbanksuche mithilfe von PubMed und Scopus durchgeführt. Danach wurde eine manuelle Suche durchgeführt, um kontrollierte Studien auszumachen, die Frauen nach einseitiger Ovarektomie mit Frauen mit 2 intakten Eierstöcken verglichen. Es wurde eine systematische Überprüfung der Fertilitätsergebnisse nach IVF durchgeführt, und die Daten wurden in einer Tabelle zusammengefasst. Bei Frauen, die sich einer einseitigen Ovarektomie unterzogen hatten, waren das Alter bei Eintritt der Wechseljahre sowie die klinischen Schwangerschaftsraten ähnlich wie bei Frauen mit 2 Eierstöcken. Es wurde zwar eine verminderte ovarielle Reserve bei Frauen nach einer einseitigen Ovarektomie festgestellt; diese wirkte sich aber auf die Quantität, nicht auf die Qualität des ovariellen Pools nach IVF aus. Es wurde ferner ein erhöhtes Risiko für neurologische Erkrankungen und sogar ein erhöhtes Mortalitätsrisiko bei Frauen mit nur einem Eierstock beobachtet. Diese Daten müssen in weiteren Studien bestätigt werden, und ein plausibler Wirkungsmechanismus dafür muss noch identifiziert werden. Nach aktuellem Wissensstand können Patientinnen, die sich einer einseitigen Ovarektomie unterziehen, hinsichtlich ihres reproduktiven Potenzials und ihres Alters bei Eintritt der Wechseljahre beruhigt sein.

\section{Introduction}

Adnexal surgery is one of the most common surgeries performed by gynecologists in clinical practice. When it is performed in women of reproductive age, surgical technique will aim to preserve as much parenchymal tissue as possible so as to preserve endocrine and reproductive function. Unfortunately, a parenchyma-preserving approach is not always possible and the entire ovary may have to be removed. This is the case when the physician finds a suspicious mass, an ovarian malignancy or a lesion that has replaced the entire parenchyma. Interestingly, Laughlin-Tommaso et al. observed that in 1838 women subjected to unilateral oophorectomy (UO) before menopause, the most frequent cause of unilateral ovarian resection was a benign condition (73.6\%), with non-malignant ovarian cysts the most common pathological finding (58.6\%) [1].

Fertility and endocrine consequences after bilateral oophorectomy are clear, with abrupt cessation of fertility and immediate menopause. Several other consequences affecting women's overall health, such as increased risk of cardiovascular and neurological disease and an increased overall risk of mortality, have been reported [2-6].

On the other hand, relatively little is known about the consequences of unilateral oophorectomy (UO). The remaining ovary after UO maintains sufficient endocrine function to avoid the occurrence of symptoms linked to bilateral oophorectomy. However, there is still relatively little knowledge about the long-term effects on women's overall health and the reproductive potential of women who have had UO.

This review aims to summarize the current evidence about the biological impact of UO. Published studies on women who had unilateral oophorectomy which reported on the impact of UO on age at onset of menopause and/or risk of cardiovascular and/or neurological disease and/or mortality risk as well as fertility were included and summarized. An overview of the known biological effects of UO in animal models is also given.

\section{Review}

\section{Unilateral oophorectomy in experimental animal models}

The biological effects relating to $U O$ have been extensively studied in different animal species. The detailed biological evidence from the animal kingdom can help to obtain a better understanding of the physiological phenomenon that occurs in the remaining ovary after the removal of the contralateral gonad.

In fishes, $\mathrm{UO}$ is associated with an increase in mass of the contralateral ovary and the reduction of follicular atresia. The growth of the remaining ovary seems to be related to an increase in the number and size of mid-to-late stage follicles without any recruitment of new primary oocytes [7]. Plasma steroid levels of fishes subjected to oophorectomy were found to be similar to those of a control group with two intact ovaries [8]. In this case, GhRH/FSH hormones appeared to be the basic regulators of the compensatory process [8].

Similar mechanisms seem to be involved in the compensatory phenomenon occurring in ovariectomized mammals. Studies carried out in rats and cows showed that the short and long-term effects of UO do not include a reduction of follicular reserve in the contralateral ovary. Even in mammals, no additional recruitment of primordial follicles occurs but the ovulatory rate within the growing follicles increases, thus allowing multiple ovulations during the same ovarian cycle. In contrast to what was observed in fishes, the number of follicles undergoing atresia in the remaining ovary remains stable, thus suggesting that the fertility preservation is not related to a reduction in atresia [9-10]. In sheep subjected to UO, compensatory mechanisms involving the remaining ovary were observed only at the end of the estrous cycle in which 
surgery was performed [11]. Immediately after surgery, the higher ovulation rate was found to be related to ovulations from multiple follicular waves of the cycle, caused by prolongation of the static phase of the largest follicle of the penultimate wave. These dynamics appeared not to be LH or FSH dependent.

Moreover, evidence about rats suggests that the two ovaries play distinct homeostatic roles and that ovarian surgery may affect the fertility potential differently, based on which ovary is removed. Two different studies revealed that the right and left ovary play different roles in maintaining normal hormone levels, that these roles change cyclically during the course of the ovarian cycle, and that the effect of ovarian denervation on hormone levels depends on which ovary is preserved $[12,13]$. In particular, when the left ovary was sacrificed, the right ovary was found to secrete higher levels of estradiol (E2) compared to the contralateral ovary, whereas in cases of right $\mathrm{UO}$, the remaining left ovary was associated with higher FSH serum level concentrations. Progesterone level concentrations, on the contrary, did not appear to be influenced by the side where oophorectomy was performed [12].

Specifically differentiating between right and left-ovariectomized animals, a previously published study carried out on squirrels showed that unilaterally ovariectomized individuals did not experience any significant difference in terms of reproductive time span and outcome, compared to the control groups [14]. On the contrary, during lactation, estradiol and progesterone serum levels were, respectively, higher and lower in squirrels with one ovary [14]. These observations confirm that a compensatory phenomenon occurs in the remaining ovary, and the higher serum estradiol level might be preventing excessive follicular compensation. Recently, a very interesting insight into adult birds with one and two ovaries and oviducts, was published, raising important and provocative questions about this issue [15].

\section{Unilateral oophorectomy in women}

In humans, it is well established that bilateral oophorectomy performed for preventive or curative reasons before the onset of menopause negatively affects women's overall health. Negative sequelae include an increased risk over time of cardiovascular [2] and neurological diseases [3], mental disorders [5] and overall mortality [6].

Although a compensatory increase in contralateral ovarian volume has been observed in unilaterally oophorectomized young women [16], the biological effects occurring after UO still remain unclear. Theoretically, if compensatory mechanisms kick in after UO, few or no effects should be expected. However, several questions still remain unanswered:

1. Is age at onset of menopause affected by UO?

2. Does the increased risk of cardiovascular and neurological diseases recorded for patients with bilateral oophorectomy apply to women who have undergone UO as well?

3. Does UO increase the risk of mortality in the same way that bilateral oophorectomy does?

4. Are the consequences, if any, of UO the same, regardless of laterality?

5. What is the impact, if any, of UO on fertility outcome?

6 . Is there really a clinical difference between ovarian cystectomy and UO?

\section{Unilateral oophorectomy and onset of menopause}

Where the removal of one ovary influences the onset of menopause in patients who are of reproductive age is still the subject of investigations. In Norway, a survey of 23580 women (the HUNT2 survey) revealed that women who had undergone UO experienced the onset of menopause one year earlier compared to women who did not (49.6 vs. 50.7 years, $p<0.001)$ [17]. This difference remained significant even after adjustment for birth cohort, parity, smoking, body mass index (BMI) and age at menarche. Although significant, this difference is small, considering that ovariectomized women were deprived of half of their follicular reserve. These results are consistent with those of a large cohort study of 24252 Japanese women that showed an earlier onset of menopause in women who had undergone UO (50.9 vs. 52.1 years, $\mathrm{HR} 1.40,95 \% \mathrm{Cl}: 1.22-1.60)$ [18].

More recently, Rosendahl et al. [19] came to the same conclusions, after demonstrating in a large cohort of 17781 Danish women that UO significantly reduces the age at onset of menopause by 1.8 years (mean 49.5 vs. 51.3 years). Furthermore, they found that younger age at UO was significantly linearly correlated to younger age at menopause.

The data in the literature are coherent in showing that onset of menopause occurs slightly earlier, suggesting that some compensatory mechanism takes place.

\section{Unilateral oophorectomy and risk of cardiovascular and neurological disorders}

Only one previous cohort study with long-term follow-up, which included 4784 women and was published 10 years ago, investigated the differences with respect to cardiovascular risk between bilateral and unilateral oophorectomy [20]. Interestingly, whereas bilateral oophorectomy increased the incidence of cardiovascular events and its correlated deaths, UO conferred some protection: women who had undergone UO had a reduced mortality associated with cardiovascular disease compared to women who had both ovaries removed ( $\mathrm{HR} 0.82 ; 95 \% \mathrm{Cl}$ : 0.67-0.99; $\mathrm{p}=0.04$ ). Although this data was both strong and surprising, the authors offered no biological reasons in support, and it needs to be confirmed by subsequent large cohort studies.

Epidemiologic studies performed at the Mayo Clinic showed that women undergoing UO before the onset of menopause have an increased risk of cognitive impairment, dementia and Parkinson disease compared to women who still have both ovaries [21, 22]. This risk seems to be of comparable magnitude to that recorded in patients who have undergone bilateral oophorectomy $[21,22]$. These data have been confirmed by Zhou et al., who showed deleterious long-term effects on cognitive function in women who underwent UO [23].

\section{Unilateral oophorectomy and mortality risk}

Data on mortality after UO are somewhat controversial. Unlike patients who undergo bilateral oophorectomy, patients with UO do not seem to have an increased mortality risk [6]. In a larger cohort of patients, the same group of researchers reported an increased overall mortality risk in patients who undergo UO before the age of 45 without concurrent hysterectomy [3]. Unlike the data recorded in the same study for patients who had undergone a bilat- 
eral oophorectomy, this increase in mortality was not related to neurological or mental disorders and the explanation remains unclear. Interestingly, considering the causal relationship between UO and women's mortality, Rice et al. [24] found, in a large cohort of unilaterally oophorectomized women, a $30 \%$ reduced risk (HR $0.70,95 \% \mathrm{Cl}: 0.53-0.91)$ of developing future ovarian cancer comparing to non-oophorectomized women, irrespective of the histological cancer subtype.

\section{Laterality of unilateral oophorectomy}

Interestingly, medically indicated unilateral oophorectomies are more commonly performed on the left side, probably secondary to the higher prevalence of endometriosis [1]. To the best of our knowledge, the effects of laterality of UO have not been investigated yet in the human setting.

Unilateral oophorectomy and spontaneous fertility

Curiously, little has been written on the effects of UO on the reproductive potential of women. In a retrospective study published in 2014, the postoperative reproductive outcome after UO was compared to that of other abdominal non-gynecological procedures such as appendectomy (AP) and cholecystectomy (CO) [25]. All surgeries were performed for benign indications. No significant differences in terms of pregnancy rates, "take home baby" rates and miscarriage rates were observed between the three groups. In particular, the rate of women who had at least one successful postoperative pregnancy was $48.5 \%$ in ovariectomized patients, $41 \%$ in patients who had appendectomy, and $53.8 \%$ in women treated with cholecystectomy (UO vs. AP, $\mathrm{p}=0.55$; UO vs. CO, $\mathrm{p}=0.99$; AP vs. $\mathrm{CO}, \mathrm{p}=0.53$ ). Large prospective studies comparing fertility outcomes between unilaterally ovariectomized women and women with two healthy ovaries are still needed.

\section{Unilateral oophorectomy and ART}

(assisted reproductive technology)

Twenty-two studies were identified which reported on ART outcomes after UO [26-45] ( Table 1$)$. Assisted reproductive tech-

- Table 1 Studies comparing fertility outcomes in women undergoing ART with or without previous unilateral oophorectomy.

\begin{tabular}{|c|c|c|c|c|}
\hline First author & Type of study & $\begin{array}{l}\text { No. of patients with } \\
\text { UO/total no. of pts. }\end{array}$ & $\begin{array}{l}\text { Indication for UO } \\
\text { no. (\%) }\end{array}$ & $\begin{array}{l}\text { Indication for ART } \\
\text { no. (\%) }\end{array}$ \\
\hline Diamond 1984 & Cohort study & $38 / 117$ & N. A. & N.A. \\
\hline \multirow[t]{5}{*}{ Alper 1985} & Cohort study & $14 / 28$ & Ectopic pregnancy 5 (36) & Endometriosis 6 (21.5) \\
\hline & & & Ovarian cyst 2 (14) & Ectopic pregnancy 6 (21.5) \\
\hline & & & Endometriosis 1 (7) & PID $12(43)$ \\
\hline & & & PID 2 (14) & Unexplained infertility 4 (14) \\
\hline & & & Unknown 4 (29) & \\
\hline \multirow[t]{6}{*}{ Dodds 1987} & Cohort study & $16 / 34$ & Ectopic pregnancy 3 (19) & Endometriosis 6 (17.65) \\
\hline & & & Ovarian cyst 1 (6) & Adhesions 12 (35.29) \\
\hline & & & Endometriosis 5 (31) & Tubal occlusion 16 (47.05) \\
\hline & & & PID 3 (19) & \\
\hline & & & Adhesions 3 (19) & \\
\hline & & & Congenital absence 1 (6) & \\
\hline Boutteville 1987 & Cohort study & $86 / 501$ & N.A. & N.A. \\
\hline Dodson 1987 & Cohort study & $\mathrm{ND} / \mathrm{ND}$ & N.A. & N.A. \\
\hline Alper 1987 & Cohort study & $10 / 18$ & N.A. & N.A. \\
\hline Lam 1987 & Cohort study & $34 / 369$ & N.A. & N.A. \\
\hline \multirow[t]{5}{*}{ Horsnstein 1989} & Cohort study & $6 / 69$ & Ectopic pregnancy 1 (16.7) & Endometriosis 5 (7.2) \\
\hline & & & Ovarian cyst 1 (16.7) & Tubal occlusion 41 (59.4) \\
\hline & & & Endometriosis 2 (33) & Unexplained infertility 6 (8.7) \\
\hline & & & PID 1 (16.7) & Multiple causes 10 (14.5) \\
\hline & & & Congenital absence 1 (16.7) & Miscellaneous 3 (5) \\
\hline Pampfer 1989 & Cohort study & $8 / 18$ & N.A. & N.A. \\
\hline \multirow[t]{4}{*}{ Khalifa 1992} & Cohort study & 135/ND & Ectopic pregnancy 23 (15) & N.A. \\
\hline & & & Ovarian cyst 24 (15.7) & \\
\hline & & & Endometriosis 72 (47) & \\
\hline & & & PID 34 (22.3) & \\
\hline
\end{tabular}


- Table 1 Studies comparing fertility outcomes in women undergoing ART with or without previous unilateral oophorectomy. (Continued)

\begin{tabular}{|c|c|c|c|c|}
\hline First author & Type of study & $\begin{array}{l}\text { No. of patients with } \\
\text { UO/total no. of pts. }\end{array}$ & $\begin{array}{l}\text { Indication for UO } \\
\text { no. (\%) }\end{array}$ & $\begin{array}{l}\text { Indication for ART } \\
\text { no. (\%) }\end{array}$ \\
\hline \multirow[t]{6}{*}{ Penzias 1993} & Cohort study & $7 / 91$ & N.A. & Endometriosis 7 (7.7) \\
\hline & & & & Tubal occlusion 54 (59.3) \\
\hline & & & & Male factor 12 (13.1) \\
\hline & & & & Diethylstilbestrol exposure 2 (2) \\
\hline & & & & Unexplained infertility 15 (16.4) \\
\hline & & & & Anovulation 1 (1) \\
\hline \multirow[t]{3}{*}{ Nargund 1995} & Case control & $17 / 39$ & Ectopic pregnancy 2 (12) & Tubal occlusion 44 (100) \\
\hline & & & Ovarian cyst 11 (64.5) & N.A. \\
\hline & & & PID 4 (23.5) & N.A. \\
\hline Lass 1997 & Case control & $58 / 939$ & N.A. & N.A. \\
\hline Levitas 2000 & Case control & $10 / 57$ & N.A. & Tubal occlusion 57 (100) \\
\hline Levi 2003 & Case control & $\mathrm{ND} / \mathrm{ND}$ & N.A. & N.A. \\
\hline \multirow[t]{3}{*}{ Al Hasani 2003} & Case control & $24 / 133$ & Ectopic pregnancy 3 (12.5) & Male factors $133(100)$ \\
\hline & & & Ovarian cyst 11 (46) & N.A. \\
\hline & & & Endometriosis 10 (41.5) & N.A. \\
\hline Asimakopoulos 2003 & Case control & $7 / 38$ & N.A. & N.A. \\
\hline Esinler 2006 & Case control & $19 / 64$ & N.A. & N.A. \\
\hline Hendricks 2010 & Cohort study & $18 / 62$ & N.A. & N. A. \\
\hline \multirow[t]{8}{*}{ Khan 2014} & Cohort study & $51 / 153$ & Ectopic pregnancy 5 (10) & Endometriosis 18 (11.7) \\
\hline & & & Ovarian cyst 17 (33) & Tubal occlusion 49 (32) \\
\hline & & & Endometriosis 13 (26) & Male factors 4 (8.3) \\
\hline & & & PID 2 (4) & Unexplained infertility 45 (29.4) \\
\hline & & & Ovarian torsion 6 (11) & Anovulation 21 (13.7) \\
\hline & & & Pelvic pain 3 (6) & Unexplained infertility 20 (13.07) \\
\hline & & & Benign tumor 2 (4) & N.A. \\
\hline & & & Malformation 3 (6) & N.A. \\
\hline \multirow[t]{7}{*}{ Wilkosz 2014} & Cohort study & $97 / 6844$ & Ectopic pregnancy 7 (7.2) & Endometriosis 1496 (21.8) \\
\hline & & & Ovarian cyst 23 (23.7) & Tubal occlusion 1603 (23.4) \\
\hline & & & Endometriosis 21 (21.6) & Male factor 2699 (39.4) \\
\hline & & & PID 8 (8.2) & $\begin{array}{l}\text { Unexplained infertility } \\
1582(23.11)\end{array}$ \\
\hline & & & Benign tumor 2 (4) & Multiple causes 364 (5.31) \\
\hline & & & $\begin{array}{l}\text { Borderline/malignant tumor } \\
7(7.2)\end{array}$ & N.A. \\
\hline & & & Unknown 12 (132.4) & \\
\hline \multirow[t]{8}{*}{ Lind 2018} & Cohort study & $154 / 22847$ & N.A. & Tubal factor 3925 (17) \\
\hline & & & & Anovulation 3679 (16) \\
\hline & & & & Endometriosis 2402 (10.5) \\
\hline & & & & Ovarian 1516 (6.6) \\
\hline & & & & Uterine/cervical cancer 68 (0.3) \\
\hline & & & & Male factors 9125 (39.9) \\
\hline & & & & Unexplained 13655 (59.7) \\
\hline & & & & Unspecified diagnosis 7196 (31) \\
\hline
\end{tabular}

UO: unilateral oophorectomy; ART: assisted reproductive technology; N. A.: not available; PID: pelvic inflammatory disease 
nology (ART) outcomes after $U O$ have been investigated in various studies with conflicting results. The majority of the series reported similar pregnancy rates between women who had undergone UO compared to women requiring ART who had both ovaries [26-36]. Other series have shown better results in patients who underwent $\mathrm{UO}$, with one series reporting better pregnancy rates in women with both ovaries [37-38,45]. A recent metaanalysis of controlled studies comparing infertile women after $\mathrm{UO}$ with women with two intact ovaries undergoing ART revealed an adverse effect of UO on ovarian reserve, which affected the quantity but not the quality of the ovarian pool [46].

After this publication, a multicenter cohort study was recently published [47,48], comparing 154 UO women with 22693 controls. It revealed lower live birth rates after IVF/ICSI in women with previous UO. The difference was significant in terms of live birth rates per started cycle (18.6 vs. $25.4 \%, p=0.007$ crude and $p=0.014$ adjusted), per ovum pick-up (20.3 vs. $27.1 \%, p=0.012$ crude and $p=0.015$ adjusted) and per embryo transfer (23.0 vs. $29.7 \%, p=0.022$ crude and $p=0.025$ adjusted), for both fresh and frozen-thawed transfers. The results contradicted those of previously published studies of the last 30 years. Nevertheless, this study includes the largest sample size of women with UO ( $n=154$ ) who underwent 301 IVF/ICSI cycles, which offered the high statistical power required to analyze live birth rate differences as a primary outcome. Although many patients in the UO group had endometriosis, thus including a potential selection bias for the presence of a poorer fertility factor in the UO group, adjustment for all known confounders did not affect the overall results. Moreover, the US national data report showed that only when endometriosis was associated with a concomitant diagnosis was the live birth rate affected [49]. In addition, the number of retrieved oocytes, embryos with a good quality morphology, and the ratio between oocyte yield and FSH score (ovarian sensitivity index) were all significantly lower in the OU group, further supporting the idea that there is both a quantitative and qualitative reduction of ovarian reserve in this patient group, decreasing the pregnancy rate. Further studies will be necessary to better clarify these contradictions and to understand the real clinical effect of UO on live birth rate in IVF/ICSI patients.

- Table 1 reports all the indications for ART and UO of patients enroled in the studies and compares fertility outcomes of women undergoing ART with or without previous unilateral oophorectomy.

\section{Unilateral oophorectomy versus cystectomy}

When treating an adnexal mass in a woman of reproductive age, an ovarian cystectomy is usually attempted to preserve as much ovarian parenchyma as possible. However, depending on the size of the mass which may occupy the site of entire ovary or in cases of suspicion of malignancy, an oophorectomy may be required in some cases.

Sometimes, very little parenchyma is left. It is unclear if an ovarian remnant may significantly contribute to the endocrine and reproductive function of the individual or whether this condition is more similar to that of women who have undergone UO.

A small prospective study of 50 patients undergoing unilateral or bilateral ovarian cystectomy for various benign conditions showed significantly decreased postoperative $\mathrm{AMH}$ serum levels at one and three months, suggesting a diminished ovarian reserve even after cystectomy [50]. This was true for endometriomas and other benign cysts and for unilateral and bilateral cystectomy. A similar prospective trial of seventy patients undergoing laparoscopic ovarian cystectomy for endometriomas and other benign ovarian cysts confirmed a short-term significant decline in ovarian reserve markers that disappeared at 6 and 12 months after the surgery, suggesting a compensatory effect of the remaining parenchyma and contralateral ovary [51]. In a recent meta-analysis on borderline ovarian tumors, no differences in oncologic outcome and pregnancy rates were recorded in women undergoing ovarian cystectomy compared to those undergoing UO [52]. In cases with borderline tumor of serous histology, ovarian cystectomy is recommended to preserve fertility despite the higher local recurrence rate, because of the high bilateral involvement associated with the disease.

\section{Conclusions}

In conclusion, certain compensatory mechanisms from the contralateral ovary that are not yet understood kick in in women who undergo UO. As a result, the age at onset of menopause of women with two ovaries differs by approximately one year from the age at onset of menopause of women who have undergone UO. However, the spontaneous reproductive potential of patients who have undergone UO seems to be similar to that of women who still have two ovaries, whereas UO has been recently associated with reduced live birth rates after IVF/ICSI techniques.

Interestingly, the compensatory mechanisms involving the contralateral ovary may not be sufficient to prevent an increased risk of neurological disease and even an increased mortality risk. These data need to be confirmed by further studies, and the plausible mechanisms of action need to be identified. At present, patients who undergo UO can be reassured with regard to their reproductive potential and their age at onset of menopause.

\section{Funding Statement}

There is no funding source for this work.

\section{Authors' Contribution}

- Conception of the work: DC and FB

- Design of the work: MLG and IR

- Acquisition of data: LT, FC, MPDM, ElB

- Analysis and interpretation of data: MLG, IR, JS, MDM, AP, DC, FB

- Drafting the final manuscript: All co-authors

- Critical revision of the final version of the manuscript before submission: All co-authors

\section{Conflict of Interest}

The authors declare that they have no conflict of interest. 


\section{References}

[1] Laughlin-Tommaso SK, Stewart EA, Grossardt BR et al. Incidence, time trends, laterality, indications, and pathological findings of unilateral oophorectomy before menopause. Menopause 2014; 21: 442-449

[2] Løkkegaard E, Jovanovic Z, Heitmann BL et al. The association between early menopause and risk of ischaemic heart disease: influence of hormone therapy. Maturitas 2006; 53: 226-233

[3] Rivera CM, Grossardt BR, Rhodes D] et al. Increased Mortality for Neurological and Mental Diseases following Early Bilateral Oophorectomy. Neuroepidemiology 2009; 33: 32-40

[4] Rocca WA, Grossardt BR, Shuster LT. Oophorectomy, estrogen, and dementia: a 2014 update. Mol Cell Endocrinol 2014; 389: 7-12

[5] Nathorst-Boos J, von Schoultz B, Carlstrom K. Elective ovarian removal and estrogen replacement therapy-effects on sexual life, psychological well-being and androgen status. J Psychosom Obstet Gynaecol 1993; 14: $283-293$

[6] Rocca W, Grossardt B, de Andrade M et al. Survival patterns after oophorectomy in premenopausal women: a population-based cohort study. Lancet Oncol 2006; 7: 821-828

[7] Luckenbach JA, Kusakabe M, Swanson P et al. Unilateral ovariectomy increases egg size and reduces follicular atresia in the semelparous coho salmon, Oncorhynchus kisutch. J Exp Zool A Ecol Genet Physiol 2008; 309: 468-476

[8] García-López Á, Sánchez-Amaya MI, Tyler CR et al. Mechanisms of oocyte development in European sea bass (Dicentrarchus labrax L.): investigations via application of unilateral ovariectomy. Reproduction 2011; 142 : 243-253

[9] Mohan M, Rajamahendran R. Effects of unilateral ovariectomy on follicular development and ovulation in cattle. Theriogenology 1998; 49: 1059-1070

[10] Aydin Y, Celiloglu M, Koyuncuoglu M et al. Follicular dynamics and apoptosis following unilateral oophorectomy. Syst Biol Reprod Med 2010; 56: $311-317$

[11] Duggavathi R, Bartlewski PM, Barrett DM et al. Short- and long-term effects of unilateral ovariectomy in sheep: causative mechanisms. Biol Reprod 2008; 78: 490-496

[12] Morales-Ledesma L, Ramírez DA, Vieyra E et al. Effects of acute unilateral ovariectomy to pre-pubertal rats on steroid hormones secretion and compensatory ovarian responses. Reprod Biol Endocrinol 2011; 9: 41

[13] Flores A, Velasco J, Gallegos AI Mendoza FD et al. Acute effects of unilateral sectioning the superior ovarian nerve of rats with unilateral ovariectomy on ovarian hormones (progesterone, testosterone and estradiol) levels vary during the estrous cycle. Reprod Biol Endocrinol 2011; 9: 34

[14] Aschauer A, Hoffmann IE, Millesi E. Endocrine profiles and reproductive output in European ground squirrels after unilateral ovariectomy. Anim Reprod Sci 2006; 92: 392-400

[15] Wessel GM. When one is (more than) enough! The singular ovary in birds... Mol Reprod Dev 2016; 83: 271

[16] Dao KA, Tadros S, Chan S et al. Pediatric ovarian volumes measured at ultrasound after contralateral unilateral oophorectomy. Pediatr Radiol 2019; 49: 632-637

[17] Bjelland EK, Wilkosz P, Tanbo TG et al. Is unilateral oophorectomy associated with age at menopause? A population study (the HUNT2 Survey). Hum Reprod 2014; 29: 835-841

[18] Yasui T, Hayashi K, Mizunuma $\mathrm{H}$ et al. Factors associated with premature ovarian failure, early menopause and earlier onset of menopause in Japanese women. Maturitas 2012; 72: 249-255

[19] Rosendahl M, Simonsen MK, Kjer J]. The influence of unilateral oophorectomy on the age of menopause. Climacteric 2017; 20: 540-544

[20] Rivera CM, Grossardt BR, Rhodes D] et al. Increased cardiovascular mortality after early bilateral oophorectomy. Menopause 2009; 16: 15-23
[21] Rocca WA, Bower JH, Maraganore DM et al. Increased risk of cognitive impairment or dementia in women who underwent oophorectomy before menopause. Neurology 2007; 69: 1074-1083

[22] Rocca WA, Bower JH, Maraganore DM et al. Increased risk of parkinsonism in women who underwent oophorectomy before menopause. Neurology 2008; 70: 200-209

[23] Zhou G, Liu J, Sun F et al. Cognitive functioning in elderly women who underwent unilateral oophorectomy before menopause. Int J Neurosci 2011; 121: 196-200

[24] Rice MS, Hankinson SE, Tworoger SS. Tubal ligation, hysterectomy, unilateral oophorectomy, and risk of ovarian cancer in the Nurses' Health studies. Fertil Steril 2014; 102: 192-198

[25] Bellati F, Ruscito I, Gasparri ML et al. Effects of unilateral ovariectomy on female fertility outcome. Arch Gynecol Obstet 2014; 290: 349-353

[26] Khalifa E, Toner JP, Muasher S] et al. Significance of basal follicle-stimulating hormone levels in women with one ovary in a program of in vitro fertilization. Fertil Steril 1992; 57: 835-839

[27] Lass A, Paul M, Margara R et al. Women with one ovary have decreased response to GnRHa/HMG ovulation protocol in IVF but the same pregnancy rate as women with two ovaries. Hum Reprod 1997; 12: 298-300

[28] Boutteville C, Muasher SJ, Acosta AA et al. Results of in vitro fertilization attempts in patients with one or two ovaries. Fertil Steril 1987; 47: 821827

[29] Asimakopoulos B, Al-Hasani S, Nikolettos N et al. A comparison of the ovarian response to external stimulation between women with right or left ovary participating in programs of ICSI/ET. Arch Gynecol Obstet 2003; 268: 168-171

[30] Alper MM, Seibel MM, Oskowitz SP et al. Comparison of follicular response in patients with one or two ovaries in a program of in vitro fertilization. Fertil Steril 1985; 44: 652-655

[31] Dodds WG, Chin N, Awadalla SG et al. In vitro fertilization and embryo transfer in patients with one ovary. Fertil Steril 1987; 48: 249-253

[32] Penzias AS, Gutmann JN, Shamma FN et al. Ovulation induction with $\mathrm{GnRH}$ agonist and human menopausal gonadotropins: response in patients with one versus two ovaries. Int J Fertil Menopausal Stud 1993; 38: $270-273$

[33] Levi R, Ozcakir HT, Alatas E et al. The outcomes of assisted reproductive technology cycles in patients with one or two ovaries. J Obstet Gynaecol Res 2003; 29: 321-325

[34] Al-Hasani S, Asimakopoulos B, Nikolettos N et al. Comparison of the response to ovarian stimulation between women with one ovary and those with two ovaries, in a program of ICSI/ET. Acta Obstet Gynecol Scand 2003; 82: 845-849

[35] Hendricks MS, Chin H, Loh SF. Treatment outcome of women with a single ovary undergoing in vitro fertilisation cycles. Singapore Med J 2010; 51: 698-701

[36] Khan Z, Gada RP, Tabbaa ZM et al. Unilateral oophorectomy results in compensatory follicular recruitment in the remaining ovary at time of ovarian stimulation for in vitro fertilization. Fertil Steril 2014; 101: 722 727

[37] Lam SY, McKenna M, McBain JC et al. Outcome of patients with one ovary in an in vitro fertilization program. J In Vitro Fert Embryo Transf 1987; 4: $319-323$

[38] Levitas E, Furman B, Shoham-Vardi I et al. Treatment outcome in women with a single ovary versus patients with two ovaries undergoing in vitro fertilization and embryo transfer (IVF/ET). Eur J Obstet Gynecol Reprod Biol 2000; 88: 197-200

[39] Nargund G, Bromhan D. Comparison of endocrinological and clinical profiles and outcome of IVF cycles in patients with one ovary and two ovaries. J Assist Reprod Genet 1995; 12: 458-460

[40] Wilkosz P, Greggains GD, Tanbo TG et al. Female reproductive decline is determined by remaining ovarian reserve and age. PLoS One 2014; 9: e108343 
[41] Diamond MP, Wentz AC, Herbert CM et al. One ovary or two: differences in ovulation induction, estradiol levels, and follicular development in a program for in vitro fertilization. Fertil Steril 1984; 41: 524-529

[42] Alper MM, Seibel MM, Oskowitz SP et al. Comparison of follicular response in patients with one or two ovaries in a program of in vitro fertilization. Fertil Steril 1985; 44: 652-655

[43] Horsnstein MD, Barbieri RL, McShane PM. Effects of previous ovarian surgery on the follicular response to ovulation induction in an in vitro fertilization program. J Reprod Med 1989; 34: 277-281

[44] Pampfer S, Vankrieken L, Loumaye E et al. Inhibin and renin in follicular fluids of patients with one or two ovaries stimulated with a GnRH agonist and gonadotrophins. Hum Reprod 1989; 4: 396-402

[45] Dodson MG, Young RL, Poindexter AN et al. Comparison of in vitro fertilization results in women with one or two ovaries. J Reprod Med 1987; 32: 359-362

[46] Younis JS, Naoum I, Salem N et al. The impact of unilateral oophorectomy on ovarian reserve in assisted reproduction: a systematic review and meta-analysis. BJOG 2018; 125: 26-35
[47] Lind T, Holte J, Olofsson JI et al. Reduced live-birth rates after IVF/ICSI in women with previous unilateral oophorectomy: results of a multicentre cohort study. Hum Reprod 2018; 33: 238-247

[48] Lind T, Oloffson JI, Berglund L et al. Reply: Is Single Ovary a Detrimenta Factor for Live-Birth Rate in IVF? Understanding the Real Clinical Effect of Unilateral Oophorectomy. Hum Reprod 2018; 33: 540-541

[49] Senapati S, Sammel MD, Morse C et al. Impact of endometriosis on in vitro fertilization outcomes: an evaluation of the Society for Assisted Reproductive Technologies Database. Fertil Steril 2016; 106: 164-171

[50] Ergun B, Ozsurmeli M, Dundar O et al. Changes in Markers of Ovarian Reserve After Laparoscopic Ovarian Cystectomy. J Minim Invasive Gynecol 2015; 22: 997-1003

[51] Ding Y, Yuan Y, Ding J et al. Comprehensive Assessment of the Impact of Laparoscopic Ovarian Cystectomy on Ovarian Reserve. J Minim Invasive Gynecol 2015; 22: 1252-1259

[52] Vasconcelos I, de Sousa Mendes M. Conservative surgery in ovarian borderline tumours: a meta-analysis with emphasis on recurrence risk. Eur J Cancer 2015; 51: 62 